\title{
Varikosel tanısında kullanılan görüntüleme yöntemleri
}

\author{
Imaging methods used in diagnosis of varicocele
}

Ali Atan

\section{öz}

Varikosel erkek infertilitesinin en sık ve düzeltilebilir bir nedenidir. Varikosel tanısında fizik muayene altın standart yöntem olmasına karşın bazı radyolojik görüntüleme yöntemlerinin kullanımı da devam etmektedir. Varikosel tanısı için kullanılan görüntüleme yöntemleri venografi, termografi, sintigrafi, bilgisayarlı tomografi ve difüzyon ağırlıklı manyetik rezonans görüntülemedir. Bu derlemede, görüntüleme yöntemleri ile ilgili güncel bilgiler verilecektir.

Anahtar Kelimeler: Varikosel, tanı, görüntüleme
$E^{t}$ rkek infertilitesinin en sık ve düzeltilebilir nedeni olan varikosel, pampiniform pleksusta bulunan venlerin anormal dilatasyonudur. ${ }^{[1]}$ S1klıkla sol tarafta görülür. Sol internal spermatik ven vertikal olarak seyrederek o taraf renal venine drene olur. Sol renal ven içerisindeki yüksek basınç varikosel oluşumuna yol açar. Sağ taraf internal spermatik ven tanjansiyel olarak vena kavaya açıldığı için ciddi bir basınca maruz kalmaz. ${ }^{[2]}$ Varikosele bağlı infertilitenin nedeni tam olarak bilinmemesine karşın 1 sı artışı, artmış veya azalmış kan akımı, renal ve adrenal metabolitlerin testise reflüsü, hipoksi, sigara, hormonal bozukluk, aile öyküsü, yaş, travma, obezite, flebit ve uzun süre ayakta kalma gibi faktörlerin rol oynadığı düşünülmektedir. ${ }^{[3-6]}$

Varikosel prevelansı sağlıklı erkeklerde \%15-20 oranındadır. Primer infertilite nedeniyle tedavi arayan erkeklerde varikosel prevelansı \%35-40 oranında iken sekonder

Gazi Üniversitesi Tıp Fakültesi, Üroloji Anabilim Dalı, Ankara, Türkiye

Yazışma Adresi / Correspondence:

Prof. Dr. Ali Atan

Birlik Mahallesi, 396 Sokak, 14/11 Çankaya, Ankara, Türkiye

Tel. $\quad+905324242082$

E-mail: aliatanpitt@hotmail.com

Geliş / Received: $\quad$ 26.04.2018

Kabul / Accepted: 12.06.2018

\section{ABSTRACT}

Varicocele is the most common and correctable cause of male infertility. Although the physical examination is the gold standard method in diagnosis of varicocele, some radiological imaging methods are still in use. Imaging methods used for varicocele diagnosis are venography, thermography, scintigraphy, computed tomography, and diffusion weighted magnetic resonance imaging. Up-to-date information on radiological imaging methods will be given in this review.

Keywords: Varicocele, diagnosis, imaging infertilite nedeniyle başvuranların ise yaklaşık \%80'inde varikosel saptanmaktadır. ${ }^{[7,8]}$ Klinik olarak anlamlı bir varikosel tanısında altın standart yöntem hala fizik muayenedir. Fizik muayeneye göre klinik varikoseller üç dereceye ayrilır. Derece 1 varikosel, küçük ve sadece valsalva ile palpe edilebilen varikoseldir. Derece 2 varikosel, istirahat durumunda palpe edilebilen varikoseldir. Derece 3 varikosel ise istirahat durumunda bile gözle görünen büyük varikoseldir. ${ }^{[9]}$ Dünya Sağlık Örgütü bu derecelendirme sistemini genişletmiş ve valsalva manevrası esnasında da palpe edilemeyen sadece ultrasonografi (US) ile saptanabilen subklinik varikoselleri eklemiştir. ${ }^{[10]}$ ASRM (American Society of Reproductive Medicine) ve AUA (American Urological Association) palpe edilmeyen varikosel tanısı içi rutin bir radyolojik incelemeyi önermemektedir. ${ }^{[11,12]}$ EAU (European Association of Urology) ise klinik varikosel tanısından sonra renkli Doppler US ile tanının teyit edilmesini önermektedir. ${ }^{[13]}$ Ancak klinik muayene sübjektiftir, muayeneyi yapan kişiler arasında anlamlı farklılık vardır, fizik muayene ile testiküler kan akımındaki değişim saptanamaz ve fizik muayene subklinik varikoseller için yeterli değildir. Bunlara ek olarak obez kişilerde, yüksek skrotal yerleşimli testislerde, skrotal veya inguinal cerrahi öyküsü olanlarda, hidrosel varlığında, postoperatif rekürren varikosellerde fizik muayene sorunludur. Bu durumlarda 
görüntüleme yöntemleri ile varikosel tanısı gerekli olabilmektedir. ${ }^{[14]}$ Ancak bazı yazarlar subklinik varikosel tanısı koymak için altın standart bir yöntemin olmadığı konusunda 1srarlıdırlar. ${ }^{[15]}$ Görüntüleme yöntemlerinin varikosel tanısı için önemli olmasının yanında varikoselin testis ve semen parametreleri üzerindeki etkisinin incelenmesinde de rolü vardır.

\section{Varikosel tanısında kullanılan görüntüleme yöntemleri}

\section{Venografi}

Venografi genellikle en duyarlı test olarak kabul edilmektedir ve klinik olarak palpe edilen varikoseli olan kişilerde spermatik ven reflüsünü \%100'e yakın gösterdiği saptanmıştır. ${ }^{[16]}$ ASRM komite raporunda venografi, varikosel taramasında önerilmemektedir. Ancak rekürren varikosel tanısında AUA, ASRM raporu ve EAU kılavuzlarında kullanımı desteklenmektedir. Özellikle cerrahi sonrası rekürren varikosel tedavisinde embolizasyon için kullanılması faydalıdır. ${ }^{[17,18]}$ Özellikle ilk cerrahinin başarısız olduğu ve kurtarma embolizasyonu yapılan kişilerin incelendiği bir çalışmada retroperitonda ve inguinal bölgede bulunan 1srarlı kollateral venlerin saptanmasında venografinin önemi vurgulanmıştır. ${ }^{[19]}$

Testiküler venografi küçük varikosellerin tanısında en güvenilir yöntem olarak kabul edilmesine, teknik varyasyonlardan çok etkilenmemesine ve değerlendirme yapan kişiler arasında değişkenlik olmamasına karşın bazı dezavantajları da vardır. Bu dezavantajlar invaziv bir işlem olması, uzun zamanda alması, kontrast madde enjeksiyonu gerekliliği ve buna bağlı $\% 0,5-1,0$ oranında mortaliteye yol açması, radyasyon kullanımı ve yüksek maliyetidir. ${ }^{[20]}$ Bununla birlikte kateter ucunun yanlış yerleştirilmesi, yüksek basınç altında venografi yapılması ve anatomik varyasyonlar yalancı pozitif ve yalancı negatif sonuçlara yol açtığı da gösterilmiştir. ${ }^{[21,22]} \mathrm{Bu}$ nedenlerle tüm hastalar için rutin kullanımı yerine sadece embolizasyon işlemi yapılacak hastalarda uygundur.

\section{Termografi}

Testisler skrotal kese içerisinde ve vücut ssısından $3-4^{\circ} \mathrm{C}$ düşük ssıda bulunurlar. ${ }^{[23]}$ Skrotumun infrared dijital termografik incelenmesi skrotal cilt yüzeyinden isı ölçümü yoluyla erken varikosel tanısında duyarlı, invaziv olmayan bir tanısal yöntemdir. ${ }^{[2]}$ Skrotumun infrared dijital termografisi skrotal alanda ısı ölçümü için oldukça duyarlı infrared kamera kullanımı ile yapılır. ${ }^{[25]}$ Termografi vücudun alt kısmı çıplak olarak ve ayakta durur iken yapılır. Hasta işlem öncesi oda isısında $\left(22-23^{\circ} \mathrm{C}\right) 10$ dakika bekletilmelidir. ${ }^{[26]}$ Hastanın bacakları yanlara açılır ve skrotum serbest şekilde sarkar halde olmalıdır. Penis karın duvarına doğru yukarı kaldırılır. Termografik kamera yaklaşık $40 \mathrm{~cm}$ mesafede hastanın ön kısmına yerleştirilir. Bazal, valsalva esnasında ve valsalvadan hemen sonra olarak üç görüntü alınır. ${ }^{[27]}$ Skrotumun infrared dijital termografisi ile semen bozukluğunun da saptanabildiği ve cerrahiye aday kişilerin saptanmasında da faydalı olduğu belirtilmektedir. ${ }^{[28]}$ Ayrıca düşük dereceli varikosellerin tanısında ve cerrahi tedavi sonrası takip döneminde de kullanılabileceği ispatlanmıştır. ${ }^{[29]}$

Objektif ve kısa sürede yapılan bir tanısal yöntem olmasına karşın geçmişte yaygın olarak kullanılmamışır. Termografik cihazlar pahalı, büyük boyutlu ve düşük rezolüsyonludur. Ayrıca görüntülerin yorumlanması için bir bilgisayar yazılımı da yoktur. Kesin tanısal kriterlerin olmaması ve yüksek maliyet bunun ana nedenleri olarak düşünülmektedir. ${ }^{[28]}$

İlgili alanlar sağ ve sol tarafta pampiniform pleksus ve testislerdeki ssı değerleridir. Varikosel varlığında termografide artmış $1 s ı$ alanları iki farklı şekilde değerlendirilir. Bazı hastalarda artmış ısı alanları etkilenmiş skrotumun üst kısmına sınırlı bir hipertemi şeklinde görülür. Buna Pattern A denir. Bazı hastalarda ise pampiniform pleksusu ve testisi içine alacak şekilde tüm etkilenmiş taraf skrotumunu içine alan bir termal dağılım saptanır. Buna Pattern B denir. Bilateral skrotal hipertemi nadirdir, var ise ileri evre varikosel bulgusudur. ${ }^{[27,30]}$ Pattern B erken müdahale için önemli bir bulgudur. Çünkü bu hastalarda testiküler fonksiyon bozukluğu riski fazladır. ${ }^{[23]}$

Merla ve arkadaşlarının 2004 yılındaki çalışmasında termografik ölçümlerde varikosel tanısı için pampiniform pleksusta ölçülen 1 sının $\geq 34^{\circ} \mathrm{C}$ olmasının ve o taraf testiste ölçülen ısının $>32^{\circ} \mathrm{C}$ olmasının gerekli olduğu ifade edilmiştir. ${ }^{[27]}$ Daha güncel bir çalışmada da bu sonuçlar desteklenmiştir. Termografik ölçümlerde varikoseli olan hastaların \%83'ünde sol pampiniform pleksusta ölçülen isının $\geq 34^{\circ} \mathrm{C}$ ve bu hastaların \%92'sinde sol taraf testiste ölçülen ısının $>32^{\circ} \mathrm{C}$ olduğu saptanmıştır. Yazarlar varikosel tanısı için termografik olarak ana bulgunun sol pampiniform pleksustaki $1 s ı n ı n \geq 34^{\circ} \mathrm{C}$ olduğunu, sol testisteki ısının $>32^{\circ} \mathrm{C}$ olmasının da varikosel göstergesi olduğunu belirtmişlerdir. Bu çalışmada varikosel tanısı için iki pampiniform pleksus arası ısı farkı da değerlendirilmiştir. İki pampiniform pleksus arası 1 s 1 fark $1 \geq 0,6^{\circ} \mathrm{C}$ ise bununda ikincil termografik bulgu olarak kabul edilmiştir. ${ }^{[24]}$ 


\section{Sintigrafi}

Sintigrafik incelemeler başka infertilite nedeni saptanamayan erkeklerde subklinik varikosel tanı ve derecelendirilmesinde ve rekürren varikosellerin tanısında doğru ve invaziv olmayan bir yöntemdir. Buna ek olarak skrotumun vasküler hemodinamisinin saptanmasında da faydalıdır. [2,31-33] Termografi sadece varikosel varlığını göstermede faydalı olmasına karşın sintigrafi spermatik vendeki reflünün varlığını ve derecesini de gösterir. ${ }^{[34,35]}$ Ancak hem sintigrafi için hem de venografi için uygulama farklılıkları ve standart tanı kriterlerinin olmaması bu yöntemlerin kullanımını kısıtlamıştır. ${ }^{[24,36,37]}$ Ayrıca sintigrafik incelemelerde intravenöz radyoizotop kullanımının gerekli olması, yayımlanmış çalışmalarda yöntem standardının olmaması, sintigrafide saptanan bozukluklar ile tedavi sonuçları arasında açık bir bağlantının olmaması sintigrafinin rutin kullanımını engellemiştir. ${ }^{[34,35]}$ US’nin yaygın kullanımı ile bu yöntemler devre dışı bırakılmıştır.

\section{Ultrasonografi (US)}

Hasta supin pozisyonda iken skrotum altına bir havlu ile destek yapılır ve 1 lık bir jel skrotuma uygulandıktan sonra yüksek frekanslı lineer bir transdüser kullanılarak (genelde >7,5 MHz) inceleme yapilır. Pampiniform pleksusta normal damar büyüklükleri $0,5-1,5 \mathrm{~mm}$ arasınd değişir ve ana drenaj veni 2 mm'e kadar büyük olabilir. ${ }^{[38]}$ US'de varikosel testisin üst ve yan kısmında bulunan çok sayıda, anekoik, kıvrımlı, tübüler yapılar olarak görülür. ${ }^{[39]}$ İntratestiküler varikosel renkli Doppler US'de yavaş akımlı anekoik intratestiküler kitleler olarak görülür. Spermatik ven ligasyonu sonrası kaybolur. ${ }^{[40]}$ Tüm intratestiküler varikoseller ekstratestiküler varikosel ile beraberdir. ${ }^{[41]}$ Düşük maliyet, invaziv olmaması, radyasyon yokluğu, kolay yapılması ve cihazın yaygın olarak bulunması US'yi hem skrotal hem testiküler patolojilerin değerlendirilmesinde tercih edilen ilk yöntem haline getirmektedir. ${ }^{[42]}$ Renkli Doppler US hem klinik hem de subklinik varikosel tanısında altın standart kabul edilmektedir. Duyarlılığı \%97 özgüllüğü \%94 bulunmuştur. ${ }^{[43,44]}$ Skrotal US'nin yaygın kullanımı subklinik varikosel tanısını arttırdı. Ancak her varikosel olgusu için US rutin olarak gerekli değildir. Obeziteye, önceden geçirilmiş skrotal cerrahiye, yüksek yerleşimli testise, küçük skrotuma veya kalın skrotum cildine bağlı fizik muayene yeterli değilse, skrotal US düşünülmelidir. ${ }^{[11,12,45]}$ Skrotal Doppler US ile testis volümü ölçümü, dilate venlerin çapı ve reflünün varlığı ve derecesi saptanır. ${ }^{[45,46]}$ Varikoselin US ile tanısı için venöz dilatasyon ve reflü durumu açısından hala standart bir kriter olmadığı belirtilmektedir. ${ }^{[2]}$
Klinik ve subklinik varikoseli olan 217 hastalık bir çalışmada istirahatte $>2,45 \mathrm{~mm}$ ven çapının varikosel tanısı için duyarlılı̆̆g $\% 84$, özgüllüğü $\% 81$ bulunmuştur. Valsalva manevrası esnasında saptanan $>2,95 \mathrm{~mm}$ venöz çapın klinik varikosel tanısında \%84 duyarlılığı ve özgüllüğü olduğu saptanmıştır. ${ }^{[47]}$ Yetişkinlerde valsalva manevrası esnasında pampiniform pleksusta ortalama maksimum ven çapının varikosel tamirini takiben semen parametreleri için prognostik bir kriter olduğu bulunmuştur. Ven çapı 3 mm'den büyük ise sonuçların daha iyi olduğu saptanmıştır. ${ }^{[48]}$ Ancak adolesanlarda maksimum ven çapının tanısal değeri tartışmalıdır. Adolesanlarda maksimum ven çapının testiküler asimetrinin ilerlemesi için güvenilir bir belirleyici olmadığı görülmüştür. ${ }^{[4]}$ Renkli Doppler US'de geri akım olmaksızın dilate venlerin görülmesi varikosel varlığını göstermez. Çünkü cerrahi olarak tedavi edilmiş varikosel olgularında ısrarlı genişlemiş venler görülebilir. ${ }^{[45]}$ Başka bir çalışmada ise renkli Doppler US ile klinik ve subklinik varikoseli olan hastalarda pampiniform pleksustaki venlerin çapı kontrol grubu ile karşılaştırılmıştır. Yazarlar klinik olarak varikoseli bulunmayan hastalarda ven çapının tanısal bir kriter olarak kullanılmamasını, ven çapının klinik varikoseli olan hastalarda varikoseli tanımak ve derecelendirmek için kullanılmasını önermişlerdir. ${ }^{[50]}$

$\mathrm{Bu}$ nedenle, reflü varikosel tanısında önemli bir kriterdir. Ancak sadece reflü de tek başına belirleyici değildir. Çünkü varikoseli olmayan kişilerin yaklaşık \%50'sinde valsalva esnasında reflü olur. Bunların $\% 70$ 'i sol tarafa lokalizedir. Bu kişilerdeki reflü yaklaşık 1 saniye süresincedir ve ortalama hız 4,5 cm/sn'dir. ${ }^{[51]}$ Varikosel hastalarında venöz reflünün dercelendirilmiştir:

a. Derece reflü (kısa): 1 saniyeden kısa süreli reflülerdir ve fizyolojik reflü olarak kabul edilir.

b. Derece reflü (orta): 1-2 saniye süren, valsalva manevrası esnasında azalan ve valsalva manevrası bitmeden önce kaybolan reflülerdir.

c. Derece reflü (kalıcı): 2 saniyeden uzun süren ve valsalva manevrası esnasında plato durumnda olan reflülerdir.

Reflüler spermatik ven çapı ile korele olmamasına karşın 3. derece reflü varlığında \%60 oranında palpe edilen varikosel saptanmıştır. Orta ve kısa süreli varikosel varlığında hiç palpe edilebilir varikosel bulunmamıştır. Subklinik varikosel tedavisi sonrası 3 . derece reflü var ise palpe edilebilir varikosel varlığında yapılan cerrahi tedavi ile benzer sonuçlar elde edilmiştir. ${ }^{[52]}$ Son yıllarda reflüye dayalı yeni bir sınıflama daha tanımlanmıştır. Buna göre, 1 sn'den kısa reflü varlığında Grade $0,1-2,5$ sn reflü varlığında Grade 1, 2,5-4 sn reflü varlığında Grade 2 ve 4 sn'den uzun bir reflü varlığında ise Grade 3 reflü olduğu belirtilmiştir. ${ }^{[4]}$ Semen 
parametreleri ile varikosel ven çapı, varikosel derecesi ve 1 sn'den uzun reflü süresi arasında anlamlı korelasyon vardır. ${ }^{[53]}$ Venöz reflü varikosel tanısı için olmakla beraber 1 sn'den uzun reflünün infertilite riskini arttırdığı da belirtilmektedir. ${ }^{[54]}$

Varikosel hastalarında US kullanımının yeni bir boyutu elastografidir. Elastografi doku sertliliğinin görüntülendiği bir yöntemdir. Varikosele bağlı testiküler doku yapısında meydana gelen değişiklikleri erken dönemde saptamayı hedefler. ${ }^{[55,56]}$ Varikosel olan testisler olmayanlara göre anlamlı derecede daha serttir. Yeni bir çalışmada elastografi değerlerinin varikoseli olmayan kontrol grubuna göre varikoseli olanlarda anlamlı derecede daha düşük olduğu saptanmıştır. Yazarlar, varikosele bağlı testis hasarının saptanmasında elastografinin fizik muayeneye göre daha faydalı olduğunu belirtmişlerdir. ${ }^{[57]}$ Çok yeni bir çalışmada da elastografinin testiküler hasarın saptanmasında faydalı olduğu konusu desteklenmektedir. ${ }^{[58]}$

\section{Abdominal Bilgisayarlı Tomografi (BT)}

Varikosel tanısında abdominal BT kullanımı rasyasyon maruziyeti nedeniyle yaygın değildir. ${ }^{[59]}$ Ancak varikosel ile beraber retroperitoneal bir hastalık veya tümör şüphesi var ise abdominal BT düşünülmelidir. Özelikle izole sağ taraf varikosel varlığında abdominal BT uygun bir görüntüleme yöntemidir. ${ }^{[60]}$

\section{Difüzyon Ağırlıklı Manyetik Rezonans (MR) Gö- rüntüleme}

Difüzyon ağırlıklı MR görüntüleme, biyolojik dokular içinde su moleküllerinin artmış veya azalmış mikroskopik difüzyon hareketlerinin ölçümüne bağlı fonksiyonel bir görüntüleme tekniğidir. Difüzyon görüntüleme ile elde edilen görünür difüzyon katsayısı (Apparent Diffusion Coefficient -ADC) değerleri su moleküllerinin hareketinin kantitatif bir ölçümüdür. Kontrast ajan enjeksiyonu gerektirmemesi ve görüntüleme zamanının kısa olması bu yöntemin avantajlarıdır. Ayrıca difüzyon ağırlıklı MR görüntüleme ile doku bütünlügü hakkında da kantitatif ve doğru bilgi elde edilebilmektedir. ${ }^{\left[{ }^{[0]}\right]} \mathrm{ADC}$ değeri dokuda difüzyon kısıtlandığında veya bozulduğunda azalmaktadır. ADC değerlerini azaltan durumlar inflamasyon, travma, tümör, iskemi, fibrozis ve sitotoksik hasardır. ${ }^{[62-66]}$

Varikoseli olan hastalarda difüzyon ağırlıklı MR görüntülemenin kullanıldığı üç klinik çalışma vardır. Bunlardan ilkinde, varikoselli testiste, karşı testiste ve sağlıklı kontrol grubunda ADC değerleri karşılaştırılmıştır. Bu çalışmada varikosel olan hastalarda varikoselli tarafta ve karşı testisteki
ADC değerlerinin sağlıklı kişilerdekinden anlamlı olarak daha düşük olduğu saptanmıştır. Ancak, varikoselli testis ile karşı testis ADC değerleri arasında anlamlı bir farklılık bulunmamıştır. ADC değerleri varikosel tanısı için \%90 duyarlılık ve \%96 özgüllük göstermiştir. ADC'nin testiküler parankimdeki fibrozise bağlı azaldığı saptanmıştır. Venöz çap arttığında ortalama ADC değerlerinin azaldığı gösterilmiştir. ${ }^{[66]}$ Yazarlar, varikoseli olan hastalarda ADC ölçümünün testiküler fibrozisin saptanmasında umut veren bir parametre olabileceğini ve gelecekte difüzyon ağırlıklı görüntülemenin varikosele bağlı testis hasarının erken tanısı için daha fazla kullanılmasının muhtemel olduğunu belirtmektedirler. ${ }^{[66]}$ Varikosel olan testiste de görülen ADC değerlerindeki azalma hipoksi ve fibrozisde artışı ile ilişkilidir. Karşı testisin etkilenmesinin hormonal ve immünolojik faktörlere ve ısı stresine bağlı olabileceği düşünülmektedir. ${ }^{[67-71]}$

Daha yeni bir çalışmada, 31 varikoseli olan erkek hastada ve 20 sağlıklı erkekte varikosele bağ $l_{1}$ ADC değerlerindeki düşüklük ile semen parametrelerindeki bozukluk arasındaki korelasyon incelendi. Varikosele bağlı ADC değerlerindeki düşüklük ile semen parametrelerindeki bozukluk arasında pozitif bir korelasyon olduğu gösterildi. ADC değerleri ne kadar fazla azalır ise sperm sayısı ve sperm morfolojisi o derece çok bozulduğu saptandı. Bu çalışmada kullanılan sınır değerlere göre $15 \mathrm{mil} / \mathrm{mL}$ den az sperm sayısı için $\left(1,131 \times 10^{-3} \mathrm{~s} / \mathrm{mm}^{2}\right)$ duyarlılığın $\% 94,3$, özgüllüğün \%86,6 olduğunu, \%4 altında normal sperm morfolojisi için $\left(1,25 \times 10^{-3} \mathrm{~s} / \mathrm{mm}^{2}\right)$ duyarılı̆̆ın $\% 87,5$, özgüllüğün \%43,8 olarak bulunmuştur. Yazarlar, ADC azalmasının geriye doğru basınç artışına bağlı oluşan iskemi ve buna bağlı fibrozis ile meydana geldiğini ifade etmişlerdir. ${ }^{[2]}$ Son çalışmada ise konvansiyonel difüzyon ağırlıklı MR görüntüleme ile yeni teknoloji olan ZOOMitt difüzyon ağırlık MR görüntüleme yöntemi kullanılarak varikoseli olan testiste, karşı testiste ve sağlık1. kontrol grubunda ADC değerleri karşılaştırılmıştır. ${ }^{[73]}$ Bu çalışmada, klasik difüzyon ağırlıklı MR görüntülemede varikoseli olan testis ADC değeri ile karşı testis ADC değerlerinde farklılık olmadığ yon ağırlıklı MR görüntülemede anlamlı bir fark olduğu saptanmıştır. Bu sonuç, yeni teknoloji difüzyon ağırlıklı görüntülemenin klasik difüzyon ağırlıklı görüntülemeye göre daha üstün olduğunun ifadesidir.

Sonuç olarak; yeni görüntüleme yöntemleri sadece tanı için değil testis hasarı, semen parametreleri ve cerrahi sonrası durum ile ilgili de bilgi vermelidir. Bu amaçla difüzyon ağılıklı MR görüntüleme yöntemlerinin kullanımının artması ve testiküler ADC düzeyleri için sınır değerlerinin belirlenmesi gereklidir. 


\section{Hakem Değerlendirmesi}

Dış bağımsız

Çıkar Çatışması

Yazarlar çıkar ilișkisi olmadığını beyan etmişlerdir.

\section{Finansal Destek}

Herhangi bir mali destek alınmamıştır.

\section{Peer-review}

Externally peer-reviewed.

\section{Conflict of Interest}

No conflict of interest was declared by the authors.

Financial Disclosure

No financial disclosure was received.

\section{KAYNAKLAR}

1. Nöske HD, Weidner W. Varicocele: a historical perspective. World J Urol 1999;17:151-7. [CrossRef]

2. Tsili AC, Xiropotamou ON, Sylakos A, Maliakas V, Sofikitis N, Argyropoulou MI. Potential role of imaging in assessing harmful effects on spermatogenesis in adult testes with varicocele. World J Radiol 2017;9:34-45. [CrossRef]

3. Shiraishi K, Matsuyama H, Takihara H. Pathophysiology of varicocele in male infertility in the era of assisted reproductive technology. Int J Urol 2012;19:538-50. [CrossRef]

4. Andò S, Giacchetto C, Colpi G, Beraldi E, Panno ML, Lombardi A, Sposato G. Physiopathologic aspects of Leydig cell function in varicocele patients. J Androl 1984;5:163-69. [CrossRef]

5. Dabaja A, Wosnitzer M, Goldstein M. Varicocele and hypogonadism. Curr Urol Rep 2013;14:309-14. [CrossRef]

6. Fujisawa M, Yoshida S, Kojima K, Kamidono S. Biochemical changes in testicular varicocele. Arch Androl 1989;22:149-59. [CrossRef]

7. Masson P, Brannigan RE. The varicocele. Urol Clin North Am 2014;41:129-44. [CrossRef]

8. Choi WS, Kim SW. Current issues in varicocele management: a review. World J Mens Health 2013;31:12-20. [CrossRef]

9. Dubin L, Amelar RD. Varicocele size and results of varicocelectomy in selected subfertile men with varicocele. Fertil Steril 1970;21:6069. [CrossRef]

10. De los Reyes T, Locke J, Afshar K. Varicoceles in the pediatric population: Diagnosis, treatment, and outcomes. Can Urol Assoc J 2017;11:34-9. [CrossRef]

11. Jarow JP, Sharlip ID, Belker AM, Lipshultz LI, Sigman M, Thomas AJ, et al. Best practice policies for male infertility. J Urol 2002;167:2138-44. [CrossRef]

12. Practice Committee of the American Society for Reproductive Medicine; Society for Male Reproduction and Urology. Report on varicocele and infertility: a committee opinion. Fertil Steril 2014;102:1556-60. [CrossRef]

13. Jungwirth A, Diemer T, Kopa Z, Krausz C, Tournaye H. Male infertility. EAU Guidelines on Male Infertility, 2017. Available at: https://uroweb.org/wp-content/uploads/Male-Infertility-2017pocket.pdf

14. Kim YS, Kim SK, Cho IC, Min SK. Efficacy of scrotal Doppler ultrasonography with the Valsalva maneuver, standing position, and resting-Valsalva ratio for varicocele diagnosis. Korean J Urol 2015;56:144-9. [CrossRef]

15. Cina A, Minnetti M, Pirronti T, Vittoria Spampinato M, Canade A, Oliva G, et al. Sonographic quantitative evaluation of scrotal veins in healthy subjects: normative values and implications for the diagnosis of varicocele. Eur Urol 2006;50:345-50. [CrossRef]

16. Ahlberg NE, Bartley O, Chidekel N, Fritjofsson A. Phlebography in varicocele scroti. Acta Radiol Diagn (Stockh) 1966;4:517-28. [CrossRef]
17. Shridharani A, Owen RC, Elkelany OO, Kim ED. The significance of clinical practice guidelines on adult varicocele detection and management. Asian J Androl 2016;18:269-75. [CrossRef]

18. Kwak N, Siegel D. Imaging and interventional therapy for varicoceles. Curr Urol Rep 2014;15:399. [CrossRef]

19. Rais-Bahrami S, Montag S, George AK, Rastinehad AR, Palmer LS, Siegel DN. Angiographic findings of primary versus salvage varicoceles treated with selective gonadal vein embolization: an explanation for surgical treatment failure. J Endourol 2012;26:556-60. [CrossRef]

20. Gat Y, Bachar GN, Zukerman Z, Belenky A, Gorenish M. Physical examination may miss the diagnosis of bilateral varicocele: a comparative study of 4 diagnostic modalities. J Urol 2004;172:1414-7. [CrossRef]

21. Nadel SN, Hutchins GM, Albertsen PC, White RI Jr. Valves of the internal spermatic vein: potential for misdiagnosis of varicocele by venography. Fertil Steril 1984;41:479-81. [CrossRef]

22. Lee J, Binsaleh S, Lo K, Jarvi K. Varicoceles: The Diagnostic Dilemma. J Androl 2008;29:143-6. [CrossRef]

23. Mieusset R, Bujan L. Testicular heating and its possible contributions to male infertility: a review. Int $\mathrm{J}$ Androl 1995;18:169-84. [CrossRef]

24. Kulis T, Kolaric D, Karlovic K, Knezevic M, Antonini S, Kastelan Z. Scrotal infrared digital thermography in assessment of varicocele - pilot study to assess diagnostic criteria. Andrologia 2012;44:7805. [CrossRef]

25. Trum JW, Gubler FM, Laan R, van der Veen F. The value of palpation, varicoscreen contact thermography and colour Doppler ultrasound in the diagnosis of varicocele. Hum Reprod 1996;11:1232-5. [CrossRef]

26. Gat Y, Zukerman ZVI, Bachar GN, Feldberg DOV, Gornish M. Adolescent varicocele: is it a unilateral disease? Urology 2003;62:742-6. [CrossRef]

27. Merla A, Ledda A, Donato LD, Romani GL. Assessment of the effects of varicocelectomy on the thermoregulatory control of the scrotum. Fertil Steril 2004;81:471-2. [CrossRef]

28. Kulis T, Knezevic M, Karlovic K, Kolaric D, Antonini S, Kastelan $Z$. Infrared digital thermography of scrotum in early selection of progressive varicocele. Med Hypotheses 2013;81:544-6. [CrossRef]

29. Gat Y, Gornish M, Chakraborty J, Perlow A, Levinger U, Pasqualotto F. Azoospermia and maturation arrest: malfunction of valves in erect poster of humans leads to hypoxia in sperm production site. Andrologia 2010;42:389-94. [CrossRef]

30. Monteyne R, Comhaire F. The thermographic characteristics of varicocele: an analysis of 65 positive registrations. Br J Urol 1978;50:118-20. [CrossRef]

31. Mali WP, Oei HY, Arndt JW, Kremer J, Coolsaet BL, Schuur K. Hemodynamics of the varicocele. Part I. Correlation among the clinical, phlebographic and scintigraphic findings. J Urol 1986;135:483-8. [CrossRef]

32. Minayoshi K, Okada H, Fujisawa M, Yamasaki K, Kamidono S. Hemodynamic evaluation of left testicular varicocele by scrotal scintigraphy. Eur Urol 2001;39:30-5. [CrossRef]

33. Fuse H, Nozaki T, Ohta S, Seto H. Sequential scrotal scintigraphy for the study of varicocele. Int Urol Nephrol 1999;31:511-7. [CrossRef]

34. Geatti O, Gasparini D, Shapiro B. A comparison of scintigraphy, thermography, ultrasound and phlebography in grading of clinical varicocele. J Nucl Med 1991;32:2092-7.

35. Paz A, Melloul M. Comparison of radionuclide scrotal blood-pool index versus gonadal venography in the diagnosis of varicocele. J Nucl Med 1998;39:1069-74. 
36. Trum JW, Gubler FM, Laan R, van der Veen F. The value of palpation, varicoscreen contact thermography and colour Doppler ultrasound in the diagnosis of varicocele. Hum Reprod 1996;11:1232-5. [CrossRef]

37. Nogueira FE, Medeiros FC, Barroso LVS, Miranda EP, de Castro JD, Mota Filho FHA. Infrared digital telethermography: a new method for early detection of varicocele. Fertil Steril 2009;92:3612. [CrossRef]

38. Wolverson MK, Houttuin E, Heiberg E, Sundaram M, Gregory J. High-resolution real-time sonography of scrotal varicocele. Am J Roentgenol 1983;141:775-9. [CrossRef]

39. Sommers D, Winter T. Ultrasonography evaluation of scrotal masses. Radiol Clin North Am 2014;52:1265-81. [CrossRef]

40. Diamond DA, Roth JA, Cilento BG, Barnewolt CE. Intratesticular varicocele in adolescents: a reversible anechoic lesion of the testis. J Urol 2004;171:381-3. [CrossRef]

41. Atasoy C, Fitoz S. Gray-scale and color Doppler sonographic findings in intratesticular varicocele. J Clin Ultrasound 2001;29:369-73. [CrossRef]

42. Studniarek M, Skrobisz-Balandowska K, Modzelewska E. Scrotal imaging. J Ultrason 2015;15:245-58. [CrossRef]

43. Dogra VS, Gottlieb RH, Oka M, Rubens DJ. Sonography of the scrotum. Radiology 2003;227:18-36. [CrossRef]

44. Patil V, Shetty SM, Das SK. Redefining the criteria for grading varicoceles based on reflux times: A clinicoradiological correlation. Ultrasound Q 2016;32:82-5. [CrossRef]

45. Coward R, Lomboy J. The Varicocele: Clinical presentation, evaluation and surgical management. Semin Intervent Radiol 2016;33:163-9. [CrossRef]

46. Khera M, Lipshultz LI. Evolving approach to the varicocele. Urol Clin North Am 2008;35:183-9. [CrossRef]

47. Pilatz A, Altinkilic B, Köhler E, Marconi M, Weidner W. Color Doppler ultrasound imaging in varicoceles: is the venous diameter sufficient for predicting clinical and subclinical varicocele? World J Urol 2011;29:645-50. [CrossRef]

48. Schiff JD, Li PS, Goldstein M. Correlation of ultrasound-measured venous size and reversal of flow with Valsalva with improvement in semen-analysis parameters after varicocelectomy. Fertil Steril 2006;86:250-2. [CrossRef]

49. Kozakowski KA, Gjertson CK, Decastro GJ, Poon S, Gasalberti A, Glassberg KI. Peak retrograde flow: A novel predictor of persistent, progressive and new onset asymmetry in adolescent varicocele. J Urol 2009;181:2717-23. [CrossRef]

50. Çaşkurlu T, Taş̧̧ı Aİ, Resim S, Şahinkanat T, Ekerbiçer $H$. Reliability of venous diameter in the diagnosis of subclinical varicocele. Urol Int 2003;71:83-6. [CrossRef]

51. Kocakoc E, Kiris A, Orhan I, Bozgeyik Z, Kanbay M, Ogur E. Incidence and importance of reflux in testicular veins of healthy men evaluated with color duplex sonography. J Clin Ultrasound 2002;30:282-7. [CrossRef]

52. Cornud F, Belin X, Amar E, Delafontaine D, Helenon O, Moreau JF. Varicocele: strategies in diagnosis and treatment. Eur Radiol 1999;9:536-45. [CrossRef]

53. Mahdavi A, Heidari R, Khezri M, Shiravi A, Pirjani R, Kashaf RS. Can Ultrasound Findings be a Good Predictor of Sperm Parameters in Patients With Varicocele? A Cross-Sectional Study. Nephrourol Mon 2016;8:e37103. [CrossRef]

54. Mihmanli I, Kurugoglu S, Cantasdemir M, Zulfikar Z, Yilmaz HM, Numan F. Color Doppler ultrasound in subclinical varicocele: an attempt to determine new criteria. Eur J Ultrasound 2000;12:43-8. [CrossRef]

55. Göya C, Daggulli M, Hamidi C, Yavuz A, Hattapoglu S, Cetincakmak MG, Teke M. The role of quantitative measurement by acoustic radiation force impulse imaging in differentiating benign renal lesions from malignant renal tumours. Radiol Med 2014;120:296-303. [CrossRef]
56. Garra BS. Elastography: history, principles, and technique comparison. Abdom Imaging 2015;40:680-97. [CrossRef]

57. Dede O, Teke M, Daggulli M, Utangaç M, Baş O, Penbegül N. Elastography to assess the effect of varicoceles on testes: a prospective controlled study. Andrologia 2016;48:257-61. [CrossRef]

58. Camoglio FS, Bruno C, Peretti M, Bianchi F, Bucci A, Scirè G, et al. The Role of Sonoelastography in the Evaluation of Testes With Varicocele. Urol 2017;100:203-6. [CrossRef]

59. Karcaaltincaba M. Demonstration of normal and dilated testicular veins by multidetector computed tomography. Jpn J Radiol 2011;29:161-5. [CrossRef]

60. Ko EYK, Belay RE, Huang GO, Shen JKC. Diagnosis of clinical and subclinical varicocele: how has it evolved? Asian J Androl 2016;18:182-5. [CrossRef]

61. Sener RN. Diffusion MRI. apparent diffusion coefficient (ADC) values in the normal brain, and a classification of brain disorders based on ADC values. Comput Med Imaging Graph 2001;25:299326. [CrossRef]

62. Kangasniemi M, Kaipia A, Joensuu R. Diffusion weighted magnetic resonance imaging of rat testes: a method for early detection of ischemia. J Urol 2001;166:2542-4. [CrossRef]

63. Mukherji SK, Chenevert TL, Castillo M. Diffusion-weighted magnetic resonance imaging. J Neuroophthalmol 2002;22:11822. [CrossRef]

64. Sandrasegaran K, Akisik FM, Lin C, Tahir B, Rajan J, Saxena R, Aisen AM. Value of diffusion-weighted MRI for assessing liver fibrosis and cirrhosis. Am J Roentgenol 2009;193:1556-60. [CrossRef]

65. Gulum M, Cece H, Yeni E, Savas M, Ciftci H, Karakas E, et al. Diffusion weighted MRI of the testis in hydrocele: a pilot study. Urol Int 2012;89:191-5. [CrossRef]

66. Karakas E, Karakas O, Cullu N, Badem OF, Boyacı FN, Gulum $\mathrm{M}$, Cece H. Diffusion-weighted MRI of the testes in patients with varicocele: a preliminary study. Am J Roentgenol 2014;202:324-8. [CrossRef]

67. Turner TT, Lopez TJ. Testicular blood flow in peripubertal and older rats with unilateral experimental varicocele and investigation into the mechanism of the bilateral response to the unilateral lesion. J Urol 1990;144:1018-21. [CrossRef]

68. Knudson G, Ross L, Stuhldreher D, Houlihan D, Bruns E, Prins G. Prevalence of sperm bound antibodies in infertile men with varicocele: the effect of varicocele ligation on antibody levels and semen response. J Urol 1994;151:1260-2. [CrossRef]

69. Goldstein M, Eid JF. Elevation of intratesticular and scrotal skin surface temperature in men with varicocele. J Urol 1989;142:7435. [CrossRef]

70. Yamaguchi M, Sakatoku J, Takihara H. The application of intrascrotal deep body temperature measurement for the noninvasive diagnosis of varicoceles. Fertil Steril 1989;52:295301. [CrossRef]

71. Zorgniotti AW, Sealfon AI. Measurement of intrascrotal temperature in normal and subfertile men. J Reprod Fertil 1988;82:563-6. [CrossRef]

72. Çekiç B, Kiliç KK, Toslak IE, Şükun A, Sağlik S, Savaş M, Köroğlu M. Correlation Between Semen Analysis Parameters and Diffusion-Weighted Magnetic Resonance Imaging of the Testicles in Patients With Varicocele: A Pilot Study. J Comput Assist Tomogr 2018;42:423-8. [CrossRef]

73. Yıldırım İO, Sağlık S, Çelik H. Conventional and ZOOMit DWI for Evaluation of Testis in Patients With Ipsilateral Varicocele. AJR Am J Roentgenol 2017;208:1045-50. [CrossRef] 